\title{
Assessment of the effectiveness of pressure ulcer care
}

\author{
Zita Gierasimovič ${ }^{1}$, Zyta Kuzborska² \\ ${ }^{1}$ Vilnius University, Lithuania \\ 2 Vilnius Gediminas Technical University, Lithuania \\ E-mails: ${ }^{1}$ zitagieras@ gmail.com (corresponding author), ${ }^{2}$ zyta.kuzborska@vgtu.lt \\ (Received 29 February 2016; accepted 22 April 2016)
}

\begin{abstract}
The article deals with the external and internal factors influencing development of pressure ulcers and the effectiveness of their care. The patients were assessed according to their age, gender and changes in their condition. The modified Norton Scale was used to assess the effectiveness of pressure ulcer care. It has been established that internal factors increase the risk of developing pressure ulcers. The effectiveness of pressure ulcer care is promoted by pressure ulcers preventative measures, medicines and skin hygiene.
\end{abstract}

Keywords: pressure ulcer care, risk factors, preventative measures.

\section{Introduction}

Pressure ulcers are necrosis of skin and tissues underlying skin [1], which occurs due to pressure over places where the bones are close to the skin (bone prominences), poor diet and other external and internal factors $[1,2]$. Scientific sources $[2,3]$ state that pressure ulcers develop more often in elderly patients or the patients who are confined to a chair or a bed, especially moisture and enuresis, as one of etiological factors, which accelerates skin damage and the appearance of pressure ulcers [3]. In European countries, according to one-time research, the risk of development of Stage I-IV pressure ulcers among different age groups accounts for $18.1 \%$. Sacrum and heels are most often affected areas of skin [3, 4], in Canada they constitute from $15.8 \%$ to $28.2 \%$ [5], prevalence of pressure ulcers in Lithuania ranges between $2.7 \%$ and $29.5 \%$ of all the hospitalized patients [6]. It is necessary to use pressure ulcer preventative measures during all the stages of providing nursing services because they reduce the risk of pressure ulcer development by more than fivefold [6]. The effectiveness of the preventative measures in treating pressure ulcers was noticed after carrying out clinical experiments. Recommendations with respect to avoidance of development of pressure ulcers have been put forward [7]. Sources of scientific literature state [8, 9] that the following actions taken by the nursing staff are conducive to development of pressure ulcers: a badly devised plan for watching development of pressure ulcers, a limited or improperly applied pressure ulcer preventative measures and a lack of knowledge, as well as forgetfulness. Though the scientific literature offers a lot of ways to solve the problems of pressure ulcer development [9] treatment of pressure ulcers is still one of the most complicated tasks, and it is especially urgent in nursing the immobile patients (those who are confined to a chair or a bed). The aim of this work is to determine the factors that influence development of pressure ulcers and the effectiveness of their care.

\section{Methods}

A retrospective data analysis of 655 patients suffering from pressure ulcers who underwent treatment in one of Vilnius hospitals between 2009 and 2014 was carried out. Samples of the respondents were selected objectively of the respondents was made. Patients who needed urgent care or were brought to hospital in a planned manner with bedsores; and patients who were already in hospital and had bedsores. The respondents' observation was done according to the number of the patients who arrived to hospital with pressure ulcers. The efficiency of bedsore care was assessed before the respondents were from hospital.

The modified Norton Scale was used to assess the effectiveness of pressure ulcer care.

(C) 2016 The Authors. Published by VGTU Press. This is an open-access article distributed under the terms of the Creative Commons Attribution License (CC-BY 4.0), which permits unrestricted use, distribution, and reproduction in any medium, provided the original author and source are credited. 
The research data have been encoded and analysed by means of the programme IBM SPSS Statistics 19.0. Differences between non-parametric indicators were established by means of the Fisher's $\chi^{2}$ (chi square) criterion. The Spearman's coefficient of rank correlation denoted by $r_{s}$ was calculated to determine strengthening of the statistical relationship. Differences were considered to be statistically significant when the value of the error probability $\mathrm{p} \leq 0,05$.

\section{Results}

In the course of carrying out the investigation between 2009 and 2014, a total of $423(64.6 \%)$ patients suffering from pressure ulcers arrived at the hospital (the minimum number of pressure ulcers was one and their maximum number amounted to 11; the median accounted for 2 pressure ulcers). As many as 232 (35.4\%) patients developed pressure ulcers while undergoing treatment in hospital (the minimum number of pressure ulcers was 8 , the median accounted for one). The average age of the patients was 61.7 years. The patients who underwent treatment at the in-patient department developed pressure ulcers within the following time period: the minimum number of pressure ulcers took one day to develop, the maximum number developed within the period of 50 days; the average was $\pm 9,55$ days and the median took 6 days to develop. Both females and males have the same possibilities for pressure ulcers to develop $(\mathrm{p}=0.001)$ (Table 1).

Table 1. Number of pressure ulcers in the patients who arrived and those who underwent treatment by gender

\begin{tabular}{|c|l|c|c|c|c|c|}
\hline \multicolumn{2}{|c|}{ Variables } & $\begin{array}{c}\text { Number of pressure } \\
\text { ulcers upon arrival } \\
\text { Abs. number (\%) } \\
(\mathrm{n}=423)\end{array}$ & $\begin{array}{c}\text { Number of pressure } \\
\text { ulcers in hospital } \\
\text { Abs. Number (\%) } \\
(\mathrm{n}=232)\end{array}$ & OR 95\% PI & $\chi 2$ & P \\
\hline \multirow{2}{*}{ Gender } & Male & $215(50.8)$ & $163(70.3)$ & $0.44[0.31-0.62]$ & 23.18 & $0.001^{*}$ \\
\cline { 2 - 8 } & Female & $208(49.2)$ & $69(29.7)$ & $2.29[1.63-3.21]$ & 23.18 & $0.001 *$ \\
\hline
\end{tabular}

Note: $*$ - statistically significant number $\mathrm{p} \leq 0.05$

Speaking about the age groups of the patients, symptoms of acute inflammation of epidermis and lesions of epidermis and dermis are eight times more frequent in the group of the patients between the ages of 41 and 50 than in the patients belonging to the age group under the age of 30 . Pressure ulcers are as much as 2.8 times more frequent in the group of patients over 61 years than those in the age group of the patients between the ages 41 and 50 (Fig. 1).

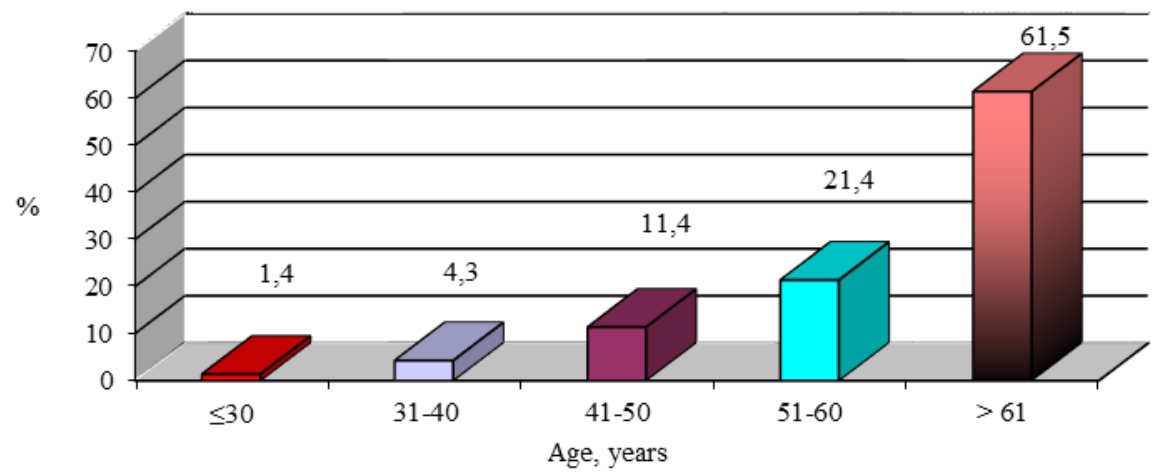

Fig. 1. Patients who developed pressure ulcers in hospital by age groups

With the duration of pressure ulcer treatment becoming longer, stage III of pressure ulcers with lesions of the deeper layers of the tissues $(p=0.001)$ was most often diagnosed in the patients, and stage IV was most often diagnosed in a group of the patients older than 61 years, as compared 
with the patients whose length of treatment was shorter $(\mathrm{p}=0.003)$. Places of localisation of pressure ulcers in the long-stay patients were assessed (Fig. 2).

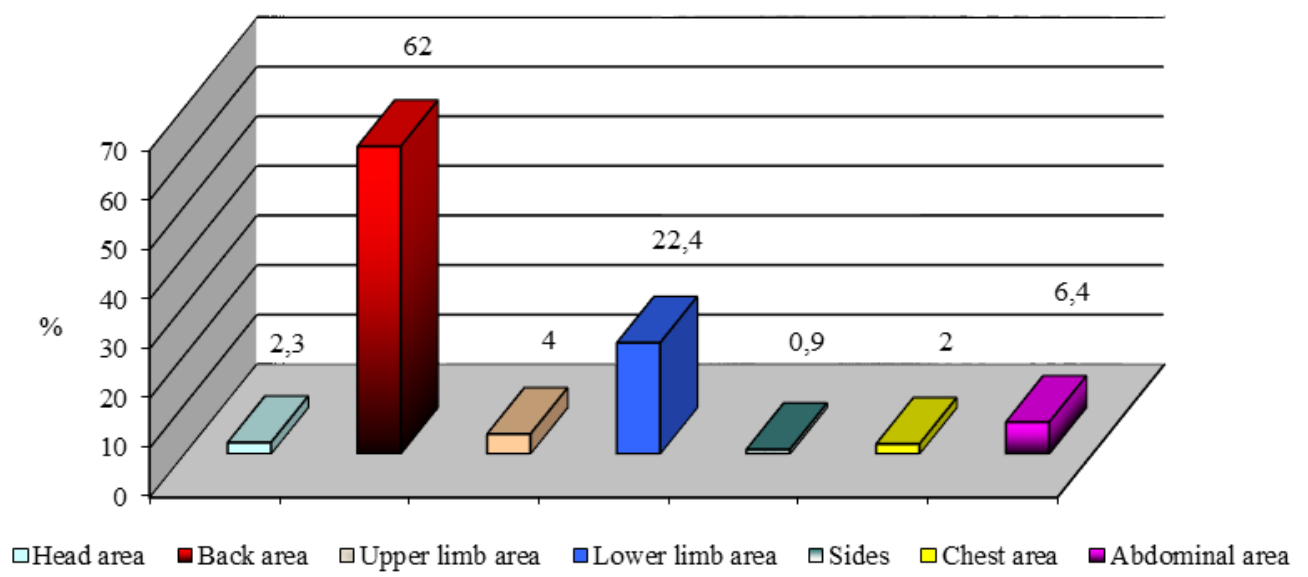

Fig. 2. Most common areas of localisation of pressure ulcers

The statistically significant difference was established in comparing the places of the localisation of pressure ulcers in the occipital lobe areas and in the region of large tubercles of the femur $(\mathrm{p}=0,001)$. With the physical condition of the patients deteriorating, the places of the localisation of pressure ulcer development increase $\left(r_{s}=-0.130 ; \mathrm{p}=0.016\right)$. An involuntary bowel movement and urination also contribute greatly to an increase in the number of pressure ulcers $\left(r_{s}=-0.108 ; \mathrm{p}=0.047\right)$.

\section{Discussion}

The research data obtained confirmed the supposition that the majority of the patients belonging to the age group of 41-50 years and older and whose physical condition was poor developed pressure ulcers 3.5 times more often that other patients. The researchers in foreign countries present similar data $[10,11]$.

Under the influence of external factors, turning the patients every two hours and more often, the probability of development of skin lesions in the back area is slight. It was established during the investigation that prolonged reddening and minor skin ulceration determine lesions in skin integrity and the localisation of a pressure ulcer of stage I in the back area in $60 \%$ of cases. It was thought that on account of external factors the frequency of turning the patient failed to meet the nursing plan devised individually for the patient. The researchers Lapsley and Vogels established that the patients' stay in hospital that was extended up to on average 11 days additionally increased the volume of nursing services by as much as $25 \%$ and that of the use of nursing facilities by $7 \%$ [12]. It was established that the patients suffering from pressure ulcers underwent treatment in hospital on average for 9.5 days and it is thought that this increases the volume of nursing services by as much as $21.6 \%$ and that of the use of nursing facility by 2.3 times.

\section{Acknowledgments}

The risk of pressure ulcer development is increased by the following external factors: the patient's age, his/her poor physical condition. Pressure ulcer preventative measures, medicines (the use of mono and combined anti-bacterial measures) and skin hygiene promote the effectiveness of pressure ulcer care. 


\section{References}

[1] Doughty, D. 2012. Differential assessment of trunk wounds: pressure ulceration versus incontinence associated dermatitis versus intertriginous dermatitis, Ostomy Wound Management 58(4): 20-22.

[2] Meesterberends, E., et al. 2011. Pressure ulcer incidence in Dutch and German nursing homes: design of a prospective multicenter cohort study, BMC Nursing 10: 8 .

http://dx.doi.org/10.1186/1472-6955-10-8

[3] Beeckman, D., et al. 2014. A systematic review and meta-analysis of incontinence-associated dermatitis, incontinence, and moisture as risk factors for pressure ulcer development, Research in Nursing \& Health 37(3): 204-218. http://dx.doi.org/10.1002/nur.21593

[4] Vanderwee, K., et al. 2007. Pressure ulcer prevalence in Europe: a pilot study, Journal of Evaluation in Clinical Practice 13(2) 227-235. http://dx.doi.org/10.1111/j.1365-2753.2006.00684.x

[5] Denny, K.; Lavand, C.; Perry, S. D. 2014. Compromised Wounds in Canada, Healthcare Quarterly 17(1): 7-10. http://dx.doi.org/10.12927/hcq.2014.23787

[6] Pečeliūnienè, R. 2012. Tinkamai parinktos priemonės - slaugomų pacientų kokybiško gyvenimo garantas, Lietuvos gydytojo žurnalas 9: 17.

[7] Gunningberg, L.; Stotts, N. A. 2008. Tracking quality over time: what do pressure ulcer data show?, International Journal for Quality in Health Care 20(4): 246-253. http://dx.doi.org/10.1093/intqhc/mzn009

[8] Baharestani, M. M., et al. 2009. Dilemmas in measuring and using pressure ulcer prevalence and incidence: an international consensus, International Wound Journal 6(2): 97-104. http://dx.doi.org/10.1111/j.1742-481X.2009.00593.x

[9] Gunningberg, L.; Brudin, L.; Idvall, E. 2010. Nurse Managers' prerequisite for nursing development: a survey on pressure ulcers and contextual factors in hospital organizations, Journal of Nursing Management 18(6): 757-766. http://dx.doi.org/10.1111/j.1365-2834.2010.01149.x

[10] Hill-Brown, S. 2011. Reduction of pressure ulcer incidence in the home healthcare setting: a pressurerelief seating cushion project to reduce the number of community-acquired pressure ulcers, Home Healthcare Nurse 29(9) 575-579. http://dx.doi.org/10.1097/NHH.0b013e31822eb830

[11] Moore, Z. E., Webster, J.; Samuriwo, R. 2014. Wound-care teams for preventing and treating pressure ulcers, Cochrane database of systematic reviews 9: CD011011.

http://dx.doi.org/10.1002/14651858.CD011011

[12] Dumville, J. C., et al. 2015. Alginate dressings for treating pressure ulcers, Sao Paulo Medical Journal 133(5): 455. http://dx.doi.org/10.1002/14651858.cd011277.pub2 